\title{
Costs of illness in amyotrophic lateral sclerosis (ALS): a cross-sectional survey in Germany
}

\author{
Erik Schönfelder \\ Hannover Medical School \\ Alma Osmanovic \\ Hannover Medical School \\ Lars Hendrik Müschen \\ Hannover Medical School \\ Susanne Petri \\ Hannover Medical School \\ Olivia Schreiber-Katz ( $\nabla$ schreiber-katz.olivia@mh-hannover.de) \\ Hannover Medical School https://orcid.org/0000-0001-5621-4487
}

\section{Research}

Keywords: Amyotrophic lateral sclerosis (ALS), cost of illness (COI), health care burden, disease cost, King's staging system, health-related quality of life (HRQoL), socioeconomic burden

Posted Date: May 12th, 2020

DOI: https://doi.org/10.21203/rs.3.rs-16042/v2

License: (c) (i) This work is licensed under a Creative Commons Attribution 4.0 International License. Read Full License

Version of Record: A version of this preprint was published at Orphanet Journal of Rare Diseases on June 12th, 2020. See the published version at https://doi.org/10.1186/s13023-020-01413-9. 


\section{Abstract}

Background Amyotrophic lateral sclerosis (ALS) is a fatal neurodegenerative disorder. Consequently, patients undergo a multidisciplinary treatment that often requires intensive use of medical resources. This study provides an estimate on the cost of illness depending on the clinical severity while also analysing the patients' health-related quality of life.

Methods Primary data from patients and caregivers was collected through a standardized questionnaire. Direct medical, direct non-medical and indirect costs were calculated using the latest German health economic guidelines. Patients were divided into five groups according to the King's staging system. Health-related quality of life was assessed using EuroQoL Group EQ-5D-5L ${ }^{\mathrm{TM}}$ questionnaire. Influencing factors on both total cost and quality of life were examined.

Results The mean annual total cost of illness was 78,256€ per patient while the lifetime cost per patient was estimated at $246,184 €$. The prevalence based total burden yearly therefore was $519,776,352 €$ in Germany. Nearly half of the costs were attributable to informal care. With increase of the clinical severity stage, costs rose and quality of life decreased. The score of the revised Amyotrophic Laterals Sclerosis Functional Rating Scale was identified as one major influencing factor on total costs, while subjective impairment in daily activities and classification into a care level as opposed to having no care level influenced patients' quality of life.

Conclusion It is essential to understand the socioeconomic burden of a disease. These data can be used to improve patient care standards and quality of life while also serving as a basis for cost-benefit analyses during the approval process of new treatments.

\section{Background}

Amyotrophic lateral sclerosis (ALS) is a progressive neurodegenerative disease that is characterised by upper and lower motor neuron loss. It leads to atrophy and weakness of voluntary muscles, bulbar symptoms like dysarthria and dysphagia and, consequently, to complete paralysis and death after an average of three to five years due to respiratory failure [1, 2]. Its incidence in Germany is estimated at 3.1/100,000, its prevalence at $8 / 100,000$ [3]. The peak age of onset is from 58 to 63 years [4]; and while there is a small proportion of familial ALS cases, the majority (90\%) is sporadic [5]. At present, ALS has no known cure; approved drugs only result in a short delay in disease progression [6, 7]. The disease typically worsens over a short period of time and causes severe impairments in the lives of patients and their families. In addition to neuroprotective medication, attempts of pharmacological and supportive alleviation of symptoms and complications are the only other therapeutic option in ALS [8, 9]. Regarding these symptomatic measures, for example respiratory support (non-invasive ventilation) and implementation of specialized multidisciplinary ALS clinics have been proven to prolong patient's life span and, on the other hand, improve their individual quality of life $[10,11]$. The increased need for multidisciplinary medical care and management from professionals and relatives leads to considerable social and economic costs [12-15].

Current cost evaluations of larger ALS patient cohorts in Germany are still missing. Therefore, this study aimed to give an estimate of these costs from a societal perspective and to relate them to the patients' health-related quality of life (HRQoL). These data may contribute to the development of improvements in the patient's care and quality of life as well as to the acceleration of approval of novel future therapies.

\section{Methods}

\section{Patient recruitment}

Data collection for this explorative cross-sectional study took place between July 2018 and February 2019. Adult patients diagnosed with clinically possible, probable (incl. lab supported) and definite ALS, following the revised El-Escorial criteria [16], were enrolled into this monocentric study if they had been treated during the past two years at Hannover Medical School (MHH), Department of Neurology. Patients with other motor neuron diseases were also enrolled but not analysed within this paper. Ethical approval for this study was obtained from the institutional ethics board of $\mathrm{MHH}$.

\section{Data collection}

After having given written consent, patients together with their main caregiving relatives answered a standardized questionnaire by hand. The questionnaire was self-designed as described before $[17,18]$ and pretested in patients with another severe motor neuron disease (spinal muscular atrophy). Besides patients' demographics and their disease course, the questionnaire recorded individual disease severity by the impairment displayed in daily activities and the details on the current care and medical treatments as the basis of cost estimation. The revised Amyotrophic Lateral Sclerosis Functional Rating Scale (ALSFRS-R), a self-reported outcome that consists of four subdomains, was used to assess disease severity. The ALSFRS-R indicates the level of impairment of distinct motor functions (bulbar, fine and gross motor and respiratory function; maximum 48 points which means no impairment and minimum 0 points which means total dependence [19]).

For further analysis, the patients were subdivided into five groups according to the King's clinical staging system for ALS [20], which was derived from the ALSFRS-R score as suggested before [21]. This system categorises the progressive clinical involvement of anatomical regions

Page 2/16 
throughout the course of the disease. Of the five King's stages, each one is associated with the number of regions involved and classified as follows: stage 1 one functional region involved; stage 2 two regions; stage 3 three regions; stage $4 \mathrm{~A}$ corresponds to nutritional failure (gastrostomy); stage 4B to respiratory failure and the indication of assisted ventilation; stage 5 corresponds to death. Health-related quality of life (HRQoL) and health status were measured by the EuroQol Group EQ-5D-5L ${ }^{\mathrm{TM}}$ in the five dimensions Mobility, Self-Care, Usual Activities, Pain/Discomfort and Anxiety/Depression [22]. These dimensions are rated in five levels from no problems (=level 1) to extreme problems (= level 5). The scores were weighted based on preference of discrete combinations of health states (e.g. 11111 or 11112 and so on). Health states were translated into an EQ-5D-5 $\mathrm{L}^{\mathrm{TM}}$ index value by use of the German value set as recommended (1 = best state, $0=$ worst state; further referred to as index value) [23]. Additionally, the patient's self-rated health on a visual analogue scale (VAS; $100=$ the best imaginable health and $0=$ worst imaginable health) was recorded (further referred to as EQ-VAS score).

\section{Cost estimation}

The total cost of illness (COI) can be subdivided in different cost categories, namely direct and indirect costs. Direct costs require direct payments from patients, insurances or third parties. They can be differentiated into direct medical (e.g. drugs, supportive medical devices, doctors' consultations, hospital treatments, surgery, rehabilitations, further therapies like physio-, ergo- and speech therapy and formal care) and nonmedical costs (e.g. travel expenses, investments in constructional alterations, legal fees and informal care - which means care provided by nonprofessional caregivers, in the majority family members). We used a micro-costing method to assess costs from a societal perspective [24].

The utilization of medical and non-medical resources was assessed retrospectively within different recall periods in order to reduce recall bias. The current status was assessed for supportive devices and formal care (for partial and complete inpatient care three or twelve months, respectively). According drugs, the individual utilisation within the past week was reported, for informal care within two weeks and within the past month for further therapies and psychological support. Outpatient physician and hospital consultations were assessed with respect to the past three months, while hospitalisations and sleep laboratory were assessed for the past six months, vaccination and rehabilitation for twelve months. Moreover, we surveyed the individual utilisation of surgery, legal support, constructional alterations and travel expenses corresponding to the reason for travelling ever since disease manifestation. The utilization of direct medical and non-medical resources (see additional file 1 ) was valued monetarily by unit prices based on the latest health economic recommendations for Germany [25-27]. Moreover, patients were asked about their current classification into a care level according to the German health care system (and acquired services). Here, higher levels indicate a greater loss of autonomy and a need for more individual support (care level 1 = low impairment of individual autonomy, care level $5=$ most severe impairment of individual autonomy with special demands for nursing care) [28]. For the calculation of informal care costs, we replaced the time of care provided by informal caregivers by the statutory minimum wage for the caring sector in Germany and thus estimated the costs that would have risen if the care had been provided by professional caregivers instead [25].

In contrast, indirect costs result from absent times from work and invalidity of the affected person (and probably his caring relative) and represent the loss of productivity. Accordingly, we used the human capital approach and calculated monetary losses due to reduction of working time, absent days and early retirement based on patient reported salary levels [27]. For a more detailed methodology of cost estimation see additional file 2 .

All costs were extrapolated to one year while we assumed a stable status over this time period. Costs were shown in Euros ( $€$ ) for the year 2018 (enquiry period).

\section{Statistical analysis}

Statistical analysis was completed using IBM SPSS $25 \AA$. Demographic data was determined using frequency tables, and normal Gaussian distribution was tested using Kolmogorov-Smirnov-test. Average differences between subgroups were tested using students T-test and correlation was tested using Spearman rank correlation coefficient. Because of the explorative character of this study, we did not adjust for multiple testing. All statistical results have to be understood as hypothesis generating and not as confirmatory. Regression analysis was done by analysing possible influencing factors in a simple linear regression model. If a variable turned out to be significant (two-sided $p$-value of $<0.05$ ) we entered it into the final multiple linear regression models.

\section{Results}

\section{Patient characterisation}

156 patients were included in the analysis (response rate 37.6\%: 187/497; the majority of patients were from Northern Germany, Lower Saxony $66.7 \%$ ). The patients' age range was from 27 to 86 with the median being 65 years (table 1 ). $60.3 \%$ were male which is in line with findings that ALS is more common in men [29]. The median disease duration from symptom onset was two years. Patients showed a different distribution of ALS phenotypes. 35.3\% reported a bulbar onset whereas 34\% reported a lower limb onset which approximates previous reports [3]. The median ALSFRS-R score was 30, ranging from 1 to 48.110 patients were classified into care levels (75.3\%) where the majority of patients had a moderate 
to most severe loss of autonomy (care levels 3-5) and were impaired in daily activities (95.5\%) or even needed the permanent attendance of another (care-giving) person 24 hours a day (39.1\%). Most patients (85.7\%) were married or lived with a partner who was the primary caregiver ( $86 \%$; see additional file 1). $17.3 \%$ had private health insurance, which is slightly more than the general proportion within the German population [30]. At the time-point of the survey, only $13.8 \%$ of patients were still working in contrast to $47.1 \%$ of caregivers (table 1 ).

\section{Utilization of medical resources}

The assessment of the use of medical (and non-medical) resources served as calculation basis for direct medical and non-medical costs (fig. 1). It reflected the present patients' care and their access according to current standards. The detailed data is shown in additional file 1.

Nearly all patients (96.2\%) were treated with further therapies. The most common was physiotherapy (82.7\%, mean visits per year: 88 ), speech therapy (62.2\%, mean visits per year: 48 ) and ergotherapy (59.6\%, mean visits per year: 45$) .84 .6 \%$ had consulted an outpatient physician during the last three months (mean visits per year: 13 ) with the most commonly frequented one being a neurologist (67.3\%). $80 \%$ made use of supportive devices. On average, every patient used seven different devices, most commonly mobility devices such as wheelchairs and walking frames (67.9\%). Inpatient rehabilitation (23.1\%) and psychological support (5.8\%) were used less frequently. There was a strong contrast between the frequency of use of formal (41.0\%) and informal (81.4\%) care. Daily, the patients needed 1.4 hours of formal care when compared to 7.6 hours of informal care. The most common form of formal care was domestic aid (31.4\%) (fig. 1).

\section{Cost of illness (COI)}

The average COI was estimated to be 78,256€ per patient yearly (table 2). Direct medical costs constituted 35.9\%, direct non-medical costs $49.1 \%$ and indirect costs $15 \%$ of total COI. The main cost driving factors were informal care (46.2\%), indirect costs (15\%) and formal care (11.4\%). Total $\mathrm{COI}$ increased with every clinical severity stage (fig. 2). There was a significant positive correlation between King's staging and total costs $\left(r_{s}=\right.$ $0.482, p<0.001)$, direct medical costs $\left(r_{s}=0.361, p<0.001\right)$ and direct non-medical costs $\left(r_{s}=0.450, p<0.001\right)$. However, there was no significant correlation between King's staging and indirect costs $\left(r_{s}=0.102, p=0.205\right)$.

Influencing factors on total annual COI are shown in table 3. Total costs increased with the decline of each point of the ALSFRS-R by $2,333 €$ ( $95 \%$ $\mathrm{Cl}[1,082 € ; 3,584 €], \mathrm{p}<0.001)$. The highest increase of costs was seen in cases where patients required invasive ventilation. In this patient group, costs were substantially higher compared to patients who did not have invasive ventilation (plus 47,803€, 95\% Cl [5,112€; 90,493€], $p=0.029$ ). If patients required the permanent attendance of a caregiver, costs rose by $22,178 €(95 \% \mathrm{Cl}[2,684 € ; 41,671 €], p=0.026)$ and if they were wheelchair dependent, costs increased by $14,081 €(95 \% \mathrm{Cl}[1,388 € ; 26,774 €], \mathrm{p}=0.030)$.

Roche et al. described a mean disease duration of 42.3 months until death and standardised time periods from disease onset to every clinical King's stage [20]. Respectively, patients reach King's stage 2 after 17.7 months, stage 3 after 23.3 months, stage 4 A after 27.7 months and stage 4B after 30.3 months. By multiplying the average time expected to be in one stage with the average costs estimated for that stage and adding the results for all stages, the lifetime costs of a patient suffering from ALS from symptom onset to death were estimated at a total of $246,184 €$. Moreover, the prevalence-based total costs in Germany can be added up to 519,776,352€ per year (prevalence of ALS 8/100,000 [3] in a population of $83,019,200$ in 2018 [31]).

\section{Health-related quality of life (HRQoL)}

HRQoL was measured by EQ-5D-5L TM. The median EQ-VAS score, which reflects the self-rated current health on a visual analogue scale from 0 to 100, was 40. The EQ-5D-5L TM index value, which is derived from five dimensions of HRQoL (Mobility, Self-Care, Usual Activities, Pain/Discomfort, Anxiety/Depression), showed a median value of 0.59 (table 1). HRQoL was inversely correlated to disease progression. There was a significant negative correlation between King's staging and EQ-VAS score $\left(r_{s}=-0.490, p<0.0005, n=141\right.$, fig. 3A) and King's staging and index value $\left(r_{s}=\right.$ $-0.477, p<0.0005, n=141$, fig. 3B). Patients already stated impairments in all five domains in King's stage 1 , but only to a lower degree (mainly no or some to moderate problems). In more advanced disease stages, severe to extreme problems or even losing the ability in the domains Mobility, Self-Care and Usual Activities overwhelmingly dominated, accentuated between King's stage 2 to stages 3, 4A and 4B. The dimensions Pain/Discomfort and Anxiety/Depression were only impaired to a low to moderate extent even in stage 4B (fig. 4).

Table 4 shows the influencing factors on the HRQoL (EQ-VAS score and index value). Patients, who stated to have general impairment in daily activities, self-rated their HRQoL to be 24.7 points lower on a visual analogue scale than patients who did not feel impaired (95\% $\mathrm{Cl}$ [-41.7; -7.7$]$, $\mathrm{p}=$ $0.005)$ and showed a decrease of 0.15 points of the index value ( $95 \% \mathrm{Cl}[-0.28 ;-0.02], \mathrm{p}=0.023)$. Decreases of 14 points in the EQ-VAS score (95\% $\mathrm{Cl}[-22.3 ;-5.6], \mathrm{p}=0.001)$ and 0.13 in the index value $(95 \% \mathrm{Cl}[-0.22 ;-0.04], \mathrm{p}=0.005)$ were observed, if a patient was classified into a care level. Moreover, wheelchair dependency (-8.8 points in the EQ-VAS score (95\% $\mathrm{Cl}[-16 ;-4], \mathrm{p}=0.030)$ and -0.17 in the index value $(95 \% \mathrm{Cl}[-0.22 ;-0.12]$. $\mathrm{p}<$ $0.0005)$ ) and also the need of permanent attendance of a caregiver $(-8.3$ in the EQ-VAS score $(95 \%$ [Cl $-16.1 ;-0.5], p=0.037)$ and -0.25 in the index value $(95 \% \mathrm{Cl}[-0.33 ;-0.16], \mathrm{p}<0.0005))$ showed to be main influencers of HRQoL. Additionally, age showed to be an influencing factor on EQ-VAS score $(-0.3,95 \% \mathrm{Cl}[-0.6 ; 0], \mathrm{p}=0.034$; table 4$)$. 


\section{Discussion}

In this study, we analysed the COI of ALS in Germany related to the already well established and disease-specific King's staging system. As far as we know, our study investigated the greatest patient cohort in Germany by now and presents an estimate for the COI of ALS, which is based on current health-economic recommendations. Our estimates give an assessment basis for further cost effectiveness studies and payer negotiations. As far as we know, cost effectiveness studies are rare in the field of ALS as it is a rare disease and treatments are limited up to date [32-35]. Nevertheless, the necessity of these studies is currently increasing due to the investigation of different new treatment approaches [36-38]. However, the conduction of cost analyses in ALS is difficult, since the health insurance companies in Germany are not transparent about their expenses [25]. Real-life expenditures of the German health system would provide a fruitful comparison; however, these are not accessible to the greater public. Our estimates for mean annual costs varied from 30,086€ (King's stage 1) to 125,871€ (King's stage 4B). This demonstrates a high socioeconomic burden even in early stages of the disease. The mean annual total COI per patient was 78,256€, which is 17 -times higher than average costs per capita in Germany (4,544€) [39]. The highest cost components were informal care costs (46.2\%) and direct medical costs (35.9\%; formal care $11.4 \%$ of total $\mathrm{COI}$ ), while indirect costs constituted $15 \%$ of total COI. Patients' family members are the main contributors to informal care in Germany $[40,41]$. In our cohort, in $94.1 \%$ of the cases the main caring person was a family member. This plays a significant role not only in terms of the psychological burden but also from a socioeconomic perspective. Caregivers of patients with chronic diseases are reported to have poorer mental and physical health compared to non-caregivers [42]. This may result in even higher ALS-related costs caused by an additional need for treatment and loss of productivity on the caregivers' side.

Compared to previous studies in neuromuscular disorders (NMD), we estimated higher informal care costs (46.2\% vs. $27 \%$ in Duchenne muscular dystrophy (DMD), 20\% in Becker muscular dystrophy (BMD), 29\% in spinal muscular atrophy (SMA) and 33.6\% in Charcot-Marie-Tooth neuropathies (CMT) $[17,18,43]$. Among different NMD, associated costs of ALS were the highest regarding both, informal care costs and total COI, which also corresponds to similar studies in the past $[12,13,15]$. In contrast, indirect costs were much higher in DMD, BMD, SMA and CMT. While in our cohort direct medical and non-medical costs were correlated to increase in clinical severity, indirect costs did not. A possible explanation for these differences may involve our cohort's demographics: as the median age was 65 and $60 \%$ were already retired at the time of the survey for non-disease related reasons, productivity loss because of ALS was low and independent from clinical severity throughout our cohort. Our study did not consider indirect costs due to premature mortality. However, these costs may probably be negligible due to the late disease onset and as the majority of patients was already retired.

We showed that COI was higher and HRQoL was lower in more advanced disease stages. The influencing factors with the highest impact on COI were the ALSFRS-R score and invasive ventilation. On the other hand, HRQoL was significantly influenced by individual impairment in daily activities and classification into a care level. Common influencing factors on both, COI and HRQoL, were wheelchair dependency and the need of presence of an additional caregiver 24 hours per day. This shows that progressive loss of autonomy and increasing functional impairment throughout disease progression is the main cause of cost increase while additionally determining a reduced self-rated quality of life.

Our analysis of HRQoL showed a difference between EQ-VAS score and index value; patients reported their health state on the EQ-VAS score to be worse than what the index value showed (Median of 40/100 versus $0.59 / 1$ ). Those results, however, are not surprising as the EQ-VAS score is known to be also influenced by factors such as perceived control, education, ethnicity, smoking and age [44], while the latter proved to be an influencing factor on EQ-VAS in our linear regression model as well.

ALS patients experience major impairments in their everyday lives and need a lot of support to maintain at least a residual independence. This is underlined by our patient cohort, in which $80 \%$ needed supportive devices, on average seven different devices per patient. In contrast, supportive devices only constituted $3.6 \%$ of total COI. While this figure may seem low, a study from the United States, which had access to "true costs" from insurance companies, confirmed this result [12]. Concerning the supply of supportive devices, we made the following substantial observations: $20.2 \%$ of patients who stated to have impairment of their mobility according to the EQ- $5 \mathrm{D}-5 \mathrm{~L}^{\mathrm{TM}}$ did not use any mobility device. Moreover, $28.9 \%$ who were impaired in self-care did not use special devices and 75.6\% who were impaired in daily activities, also did not use support in this regard. While depression is known to occur in $22.8 \%$ of patients with ALS [45], only $5.8 \%$ made use of psychological support. Interestingly, of 52 patients who stated a need for improvement in disease related support, 15 (28.8\%) wished for support in the application for supportive medical devices and 12 (23\%) for better and easier accessible psychological support. Similarly, regarding the ALSFRS-R results, of 88 patients who experienced dyspnoea, 52 (59.1\%) did not use any breathing assistance. These findings strongly suggest a supply gap in these areas and maybe especially in the medical supply with more costly devices like ventilators (and the associated care that is needed with them). Better access to support and, perhaps, even costlier devices to maintain a higher grade of autonomy would raise the ratio of costs for supportive devices. Nevertheless, a supply in agreement with standards of care is necessary and not only increases the individual quality of life but also may lower other cost factors like informal care costs or indirect costs.

Our estimate of a total annual COI of 78,256€ in Germany is higher than previously assumed by Schepelmann et al. in 2010 (36,380€) [15]. Compared to previous studies in other countries, e.g. Spain $(36,194 €)$ [13], US $(63,693 \$)$ [12] and Korea $(90,000 \$)$ [14], our estimates are on the higher side of estimated costs. However, direct comparisons must be done with caution due to respective healthcare systems and different 
approaches in cost estimation. Regardless, previous studies also described disease severity, need for a caregiver, wheelchair dependency and invasive ventilation as main cost influencing factors [12,15], which further validates our model.

Compared to other NMD such as Myasthenia gravis (14,950€) [15], CMT (17,427€) [43], facioscapulohumeral muscular dystrophy (26,240€) [15] and BMD $(39,060 €)$ [17] total COI of ALS is notably higher, similar to those of DMD $(78,913 €)[17]$ and SMA $(70,566 €)[18]$. Due to a higher prevalence of ALS, the Germany-wide annual cost was $519,776,352 €$ which is more than three times higher than the estimates for DMD and nearly five times higher than the estimates for SMA.

To estimate informal care costs, we used a replacement cost approach, which is known to result in overestimation due to informal care being considered less efficient than formal [24]. On the other hand, the associated psychological and physical burden of the caregivers who provided informal care was not reflected and may result in substantial underestimation of costs. Since our questionnaire was rather detailed with more than 120 questions, a selection bias towards more motivated patients might be likely. Moreover, patients were asked to answer questions regarding use of medical resources up to one year in the past, which probably led to recall bias, and further reduced total COI. Another limitation of our study is the monocentric design and coverage mainly of Northern Germany. A multicentre Germany-wide study that employs a greater patient cohort would be desirable to achieve an even more representative result. Thus, further studies of disease burden of ALS that also consider the burden of the caregivers are necessary.

\section{Conclusion}

The results of our descriptive study confirm previous publications and show that costs in ALS increase with disease severity, are much higher than in other NMD and are mainly influenced by patients' individual autonomy status. Loss of autonomy and disease progression also significantly reduce the self-rated quality of life. Our study underlines that ALS ranks among the most costly neurological diseases and therefore, even though it is a rare disease, contributes to a high socioeconomic burden. Search for novel therapies therefore may not only contribute to a better prognosis and quality of life of patients but also might lower societal costs if the disease progression could be stopped in early disease stages.

Nevertheless, further cost analyses and cost effectiveness studies in ALS are mandatory.

Our data further highlight the urgent need of a direct and straightforward access to recommended therapies and supportive devices as well as psychological support for all patients. Formal care should be improved to reduce patient and caregiver burden and thus informal care costs and indirect costs.

\section{Declarations}

\section{Ethics approval and consent to participate}

Ethical approval for this study was obtained from the institutional ethics board of MHH (no. 7922_BO_K_2018). All study participants gave their written consent to participate in this study.

\section{Consent for publication}

All study participants gave their written consent to the publication of anonymous (cohort) data.

\section{Availability of data and materials}

The datasets used and/or analysed during the current study are available from the corresponding author on reasonable request.

\section{Competing interests}

The authors declared the following potential conflicts of interest with respect to the research, authorship, and/or publication of this article:

ES reports no conflicts of interest.

AO has received honoraria as a speaker/consultant from the German Neuromuscular Society “Deutsche Gesellschaft fuer Muskelkranke (DGM e.V.)" and Biogen GmbH. She has received academic research support by PRACTIS - Clinician Scientist Program of Hannover Medical School, funded by the German Research Foundation (DFG, ME 3696/3-1).

LHM reports no conflicts of interest.

SP has received grants by the German Neuromuscular Society (Deutsche Gesellschaft fuer Muskelkranke (DGM e.V.)), the Federal Ministry of Education and Research (BMBF), the German Israeli Foundation (GIF) for Scientific Research and Development and the EU Joint Programme for Neurodegenerative Disease Research (JPND). She has received speaking honoraria from Desitin Pharma, Biogen GmbH, Novartis and TEVA as well as fees for consulting from Biogen $\mathrm{GmbH}$, Roche Pharma, Cytokinetics Inc. 
OSK has received honoraria as a speaker/consultant and/or funding for travel expenses from the German Neuromuscular Society (Deutsche Gesellschaft fuer Muskelkranke (DGM e.V.)), Novartis, Biogen GmbH and the Jain Foundation. She has received academic research support by the Ludwig-Maximilians-University of Munich, FoeFoLe program, Reg.-No. 747, 11/11-05/13, and the Hannover Medical School Young Faculty Program, 2018-2020. She has received research support from the Friedrich-Baur-GmbH, Burgkunstadt 12/13-12/15 and the German Neuromuscular Society “Deutsche Gesellschaft fuer Muskelkranke (DGM e.V.), 2019-2020.

\section{Funding}

Deutsche Forschungsgemeinschaft PRACTIS (Program of Hannover Medical School for Clinician Scientists) (grant to A. Osmanovic). German Neuromuscular Society (Deutsche Gesellschaft fuer Muskelkranke (DGM e.V.)), Federal Ministry of Education and Research, German Israeli Foundation for Scientific Research and Development, EU Joint Programme for Neurodegenerative Disease Research (grants to S. Petri). Academic research support by MHH Young Faculty Program, 2018-2020, as well as research support by the German Neuromuscular Society (Deutsche Gesellschaft fuer Muskelkranke (DGM e.V.)), 2019-2020 (grants to O. Schreiber-Katz).

\section{Author contributions}

ES played a major role in the acquisition, analysis and interpretation of data, drafted the manuscript and set the figures and tables in this manuscript.

AO supported the patient recruitment and revised the manuscript for intellectual content.

LHM supported the patient recruitment and revised the manuscript for intellectual content.

SP took part in the creation of the study concept and design and revised the manuscript for intellectual content.

OSK played a major role in the creation of the study concept and design, was the study supervisor, designed the questionnaire with input from the other authors, took part in the acquisition, analysis and interpretation of data and revised the manuscript.

\section{Acknowledgements}

The authors thank Prof. Dr. rer. pol. Christian Krauth, Institute for Epidemiology, Social Medicine and Health Systems Research, Hannover Medical School, for his input in questionnaire design. We thank Sebastian Häckl, M. Sc. Public Health, Institute for Biostatistics, Hannover Medical School, for advice during the statistical analysis process, and James Mesiti for his insight regarding the language and expression. We also thank the German Neuromuscular Society (Deutsche Gesellschaft fuer Muskelkranke (DGM e.V.)) for funding the study. Most importantly, we thank all study participants and their caregivers.

\section{Abbreviations}

ALS Amyotrophic lateral sclerosis

ALSFRS-R Revised Amyotrophic Laterals Sclerosis Functional Rating Scale

BMD Becker muscular dystrophy

Cl Confidence interval

CMT Charcot-Marie-Tooth disease

COI Cost of illness

DMD Duchenne muscular dystrophy

EQ-VAS Self-rated health on a visual analogue scale (0-100)

HRQoL Health-related quality of life

MHH Hannover Medical School

NMD Neuromuscular disorders

SMA Spinal muscular atrophy

\section{References}


1. Zarei S, Carr K, Reiley L, Diaz K, Guerra O, Altamirano PF, Pagani W, Lodin D, Orozco G, Chinea A. A comprehensive review of amyotrophic lateral sclerosis. Surg Neurol Int. 2015;6:171. https://doi.org/10.4103/2152-7806.169561

2. Foster LA, Salajegheh MK. Motor Neuron Disease: Pathophysiology, Diagnosis, and Management. Am J Med. 2019;132(1):32-37. https://doi.org/10.1016/j.amjmed.2018.07.012

3. Rosenbohm A, Peter R, Erhardt S, Lulé D, Rothenbacher D, Ludolph A, Nagel G. Epidemiology of amyotrophic lateral sclerosis in Southern Germany. J Neurol. 2017;264(4):749-757. https://doi.org/10.1007/s00415-017-8413-3

4. Kiernan, MC, Vucic, S, Cheah, BC, Turner, MR, Eisen, A, Hardiman, O, Burrell, JR, Zoing, MC. Amyotrophic lateral sclerosis. The Lancet. 2011;377(9769):942-955. https://doi.org/10.1016/S0140-6736(10)61156-7

5. Swinnen B, Robberecht W. The phenotypic variability of amyotrophic lateral sclerosis. Nat Rev Neurol. 2014;10(11):661-670. https://doi.org/10.1038/nrneurol.2014.184

6. Miller RG, Mitchell JD, Moore DH. Riluzole for amyotrophic lateral sclerosis (ALS)/motor neuron disease (MND). Cochrane Database Syst Rev. 2012;(3):CD001447. https://doi.org/10.1002/14651858.CD001447.pub3

7. Abe K, Itoyama Y, Sobue G, Tsuji S, Aoki M, Doyu M, Hamada C, Kondo K, Yoneoka T, Akimoto M, Yoshino H. Confirmatory double-blind, parallel-group, placebo-controlled study of efficacy and safety of edaravone (MCl-186) in amyotrophic lateral sclerosis patients. Amyotroph Lateral Scler Frontotemporal Degener. 2014;15(7-8):610-617. https://doi.org/10.3109/21678421.2014.959024

8. Miller RG, Jackson CE, Kasarskis EJ, England JD, Forshew D, Johnston W, Kalra S, Katz JS, Mitsumoto H, Rosenfeld J, Shoesmith C, Strong MJ, Woolley SC. Practice parameter update: the care of the patient with amyotrophic lateral sclerosis: drug, nutritional, and respiratory therapies (an evidence-based review): report of the Quality Standards Subcommittee of the American Academy of Neurology. Neurology. 2009;73(15):1218-1226. https://doi.org/10.1212/WNL.0b013e3181bc0141

9. Hobson EV, McDermott CJ. Supportive and symptomatic management of amyotrophic lateral sclerosis. Nat Rev Neurol. 2016;12(9):526-538. https://doi.org/10.1038/nrneurol.2016.111

10. Bourke SC, Tomlinson M, Williams TL, Bullock RE, Shaw PJ, Gibson GJ. Effects of non-invasive ventilation on survival and quality of life in patients with amyotrophic lateral sclerosis: a randomised controlled trial. Lancet Neurol. 2006;5(2):140-147. https://doi.org/10.1016/S14744422(05)70326-4

11. Chiò A, Bottacchi E, Buffa C, Mutani R, Mora G. Positive effects of tertiary centres for amyotrophic lateral sclerosis on outcome and use of hospital facilities. J Neurol Neurosurg Psychiatry. 2006;77(8):948-950. https://doi.org/10.1136/jnnp.2005.083402

12. Larkindale J, Yang W, Hogan PF, Simon CJ, Zhang Y, Jain A, Habeeb-Louks EM, Kennedy A, Cwik VA. Cost of illness for neuromuscular diseases in the United States. Muscle Nerve. 2014;49(3):431-438. https://doi.org/10.1002/mus.23942

13. López-Bastida J, Perestelo-Pérez L, Montón-Alvarez F, Serrano-Aguilar P, Alfonso-Sanchez JL. Social economic costs and health-related quality of life in patients with amyotrophic lateral sclerosis in Spain. Amyotroph Lateral Scler. 2009;10(4):237-243. https://doi.org/10.1080/17482960802430781

14. Oh J, An JW, Oh S, Oh KW, Kim JA, Lee JS, Kim SH. Socioeconomic costs of amyotrophic lateral sclerosis according to staging system. Amyotroph Lateral Scler Frontotemporal Degener. 2015;16(3-4):202-208. https://doi.org/10.3109/21678421.2014.999791

15. Schepelmann K, Winter Y, Spottke AE, Claus D, Grothe C, Schröder R, Heuss D, Vielhaber S, Mylius V, Kiefer R, Schrank B, Oertel WH, Dodel R. Socioeconomic burden of amyotrophic lateral sclerosis, myasthenia gravis and facioscapulohumeral muscular dystrophy. J Neurol. 2010;257(1):15-23. https://doi.org/10.1007/s00415-009-5256-6

16. Ludolph A, Drory V, Hardiman O, Nakano I, Ravits J, Robberecht W, Shefner J. A revision of the El Escorial criteria - 2015. Amyotroph Lateral Scler Frontotemporal Degener. 2015;16(5-6):291-292. https://doi.org/10.3109/21678421.2015.1049183

17. Schreiber-Katz O, Klug C, Thiele S, Schorling E, Zowe J, Reilich P, Nagels KH, Walter MC. Comparative cost of illness analysis and assessment of health care burden of Duchenne and Becker muscular dystrophies in Germany. Orphanet J Rare Dis. 2014;9:210-9. https://doi.org/10.1186/s13023-014-0210-9

18. Klug C, Schreiber-Katz O, Thiele S, Schorling E, Zowe J, Reilich P, Walter MC, Nagels KH. Disease burden of spinal muscular atrophy in Germany. Orphanet J Rare Dis. 2016;11(1):58. https://doi.org/10.1186/s13023-016-0424-0

19. Cedarbaum JM, Stambler N, Malta E, Fuller C, Hilt D, Thurmond B, Nakanishi A. The ALSFRS-R: a revised ALS functional rating scale that incorporates assessments of respiratory function. BDNF ALS Study Group (Phase III). J Neurol Sci. 1999;169(1-2):13-21. https://doi.org/10.1016/s0022-510x(99)00210-5

20. Roche JC, Rojas-Garcia R, Scott KM, Scotton W, Ellis CE, Burman R, Wijesekera L, Turner MR, Leigh PN, Shaw CE, Al-Chalabi A. A proposed staging system for amyotrophic lateral sclerosis. Brain. 2012;135(3):847-852. https://doi.org/10.1093/brain/awr351

21. Balendra R, Jones A, Jivraj N, Knights C, Ellis CM, Burman R, Turner MR, Leigh PN, Shaw CE, Al-Chalabi A. Estimating clinical stage of amyotrophic lateral sclerosis from the ALS Functional Rating Scale. Amyotroph Lateral Scler Frontotemporal Degener. 2014;15(3-4):279-284. https://doi.org/10.3109/21678421.2014.897357 
22. Herdman M, Gudex C, Lloyd A, Janssen M, Kind P, Parkin D, Bonsel G, Badia X. Development and preliminary testing of the new five-level version of EQ-5D (EQ-5D-5L). Qual Life Res. 2011;20(10):1727-1736. https://doi.org/10.1007/s11136-011-9903-X

23. Ludwig K, Graf von der Schulenburg JM, Greiner W. German Value Set for the EQ-5D-5L. Pharmacoeconomics. 2018;36(6):663-674. doi:10.1007/s40273-018-0615-8

24. Krauth C. Methoden der Kostenbestimmung in der gesundheitsökonomischen Evaluation [Cost Estimation Methods in Health Economic Evaluation]. Gesundh ökon Qual manag 2010;15(5): 251-259. doi: 10.1055/s-0029-1245680

25. Bock JO, Brettschneider C, Seidl H, Bowles D, Holle R, Greiner W, König HH. Standardisierte Bewertungssätze aus gesellschaftlicher Perspektive für die gesundheitsökonomische Evaluation. Baden-Baden: Nomos Verlagsgesellschaft; 2015.

26. Bock JO, Brettschneider C, Seidl H, Bowles D, Holle R, Greiner W, König HH. Ermittlung standardisierter Bewertungssätze aus gesellschaftlicher Perspektive für die gesundheitsökonomische Evaluation [Calculation of standardised unit costs from a societal perspective for health economic evaluation]. Gesundheitswesen. 2015;77(1):53-61. https://doi.org/10.1055/s-0034-1374621

27. Krauth C, Hessel F, Hansmeier T, Wasem J, Seitz R, Schweikert B. Empirische Bewertungssätze in der gesundheitsökonomischen Evaluation ein Vorschlag der AG Methoden der gesundheitsökonomischen Evaluation (AG MEG) [Empirical standard costs for health economic evaluation in Germany - a proposal by the working group methods in health economic evaluation]. Gesundheitswesen. 2005;67(10):736746. doi:10.1055/s-2005-858698

28. Bundesgesundheitsministerium. Pflegegrade. 2018. https://www.bundesgesundheitsministerium.de/pflegegrade.html. Accessed 11 December 2019

29. Manjaly ZR, Scott KM, Abhinav K, Wijesekera L, Ganesalingam J, Goldstein LH, Janssen A, Dougherty A, Willey E, Stanton BR, Turner MR, Ampong M, Sakel M, Orrell RW, Howard R, Shaw CE, Leigh PN, Al-Chalabi A. The sex ratio in amyotrophic lateral sclerosis: A population based study. Amyotroph Lat Scler. 2010;11(5):439-442. https://doi.org/10.3109/17482961003610853

30. Bundesgesundheitsministerium. Gesetzliche Krankenversicherung: Mitglieder, mitversicherte Angehörige und Krankenstand, Jahresdurchschnitt 2018. 2019.

https://www.bundesgesundheitsministerium.de/fileadmin/Dateien/3_Downloads/Statistiken/GKV/Mitglieder_Versicherte/KM1_JD_2018.pdf. Accessed 24 June 2019

31. Statistisches Bundesamt. Bevölkerung auf Grundlage des Zensus 2011 nach Geschlecht und Staatsangehörigkeit im Zeitverlauf. 2019. https://www.destatis.de/DE/Presse/Pressemitteilungen/2019/06/PD19_244_12411.html. Accessed 24 June 2019

32. Pharmacoeconomic Review Report: Edaravone (Radicava): (Mitsubishi Tanabe Pharma Corporation). Ottawa (ON): Canadian Agency for Drugs and Technologies in Health; 2019.

33. Fiorentino G, Esquinas AM. Cost-effectiveness associated with amyotrophic lateral sclerosis: some questions and answers pending. Amyotroph Lateral Scler Frontotemporal Degener. 2018;19(3-4):315-316. doi:10.1080/21678421.2017.1408126

34. Gruis KL, Chernew ME, Brown DL. The cost-effectiveness of early noninvasive ventilation for ALS patients. BMC Health Serv Res. $2005 ; 5: 58$. Published 2005 Aug 30. doi:10.1186/1472-6963-5-58

35. Ginsberg G, Lowe S. Cost effectiveness of treatments for amyotrophic lateral sclerosis: a review of the literature. Pharmacoeconomics. 2002;20(6):367-387. doi:10.2165/00019053-200220060-00002

36. Okano H, Yasuda D, Fujimori K, Morimoto S, Takahashi S. Ropinirole, a New ALS Drug Candidate Developed Using iPSCs. Trends Pharmacol Sci. 2020;41(2):99-109. doi:10.1016/j.tips.2019.12.002

37. Cappella M, Ciotti C, Cohen-Tannoudji M, Biferi MG. Gene Therapy for ALS-A Perspective. Int J Mol Sci. 2019;20(18):4388. Published 2019 Sep 6. doi:10.3390/ijms20184388

38. Carpanini SM, Torvell M, Morgan BP. Therapeutic Inhibition of the Complement System in Diseases of the Central Nervous System. Front Immunol. 2019;10:362. Published 2019 Mar 4. doi:10.3389/fimmu.2019.00362

39. Statistisches Bundesamt. Gesundheitsausgaben im Jahr 2017. 2019. https://www.destatis.de/DE/Themen/GesellschaftUmwelt/Gesundheit/Gesundheitsausgaben/_inhalt.html. Accessed 24 June 2019

40. Wetzstein M, Rommel A, Lange C. Informal caregivers - Germany's largest nursing service. 610 Medizin. Robert-Koch-Institut. GBE kompakt vol. 6 no. 3. 2016. https://doi.org/10.25646/3065

41. Chiò A, Gauthier A, Calvo A, Ghiglione P, Mutani R. Caregiver burden and patients' perception of being a burden in ALS. Neurology. 2005;64(10):1780-1782. https://doi.org/10.1212/01.WNL.0000162034.06268.37

42. Butterworth P, Pymont C, Rodgers B, Windsor TD, Anstey KJ. Factors that explain the poorer mental health of caregivers: Results from a community survey of older Australians. Aust N Z J Psychiatry. 2010;44(7):616-624. https://doi.org/10.3109/00048671003620202

43. Schorling E, Thiele S, Gumbert L, Krause S, Klug C, Schreiber-Katz O, Reilich P, Nagels K, Walter MC. Cost of illness in Charcot-Marie-Tooth neuropathy: Results from Germany. Neurology. 2019;92(17):e2027-e2037. https://doi.org/10.1212/WNL.0000000000007376

44. Whynes DK. Correspondence between EQ-5D health state classifications and EQ VAS scores. Health and Quality of Life Outcomes $2008,6: 94$. https://doi.org/10.1186/1477-7525-6-94

Page 9/16 
45. Körner S, Kollewe K, Ilsemann J, Müller-Heine A, Dengler R, Krampfl K, Petri S. Prevalence and prognostic impact of comorbidities in amyotrophic lateral sclerosis. Eur J Neurol. 2013;20(4):647-654. https://doi.org/10.1111/ene.12015

\section{Tables}

Table 1 Demographics

\begin{tabular}{|c|c|c|}
\hline Age, y & $65(17)$ & \\
\hline Sex, female & 39.7 & 62 \\
\hline BMI & $24.03(5.12)$ & \\
\hline Type of health insurance $(\mathrm{n}=150)$, statutory & 82.7 & 124 \\
\hline Symptom onset, y & $62(17.8)$ & \\
\hline Disease duration from symptom onset, $\mathrm{y}$ & $2(3)$ & \\
\hline Inherited ALS & 3.8 & 6 \\
\hline ALSFRS-R score (max. 48) & $30(16)$ & \\
\hline \multicolumn{3}{|l|}{ King's staging } \\
\hline 1 & 12.8 & 20 \\
\hline 2 & 26.3 & 41 \\
\hline 3 & 28.2 & 44 \\
\hline $4 \mathrm{~A}$ & 10.3 & 16 \\
\hline $4 \mathrm{~B}$ & 22.4 & 35 \\
\hline \multicolumn{3}{|l|}{ Level of care $(n=146)$} \\
\hline none & 24.7 & 36 \\
\hline 1 & 2.1 & 3 \\
\hline 2 & 11.6 & 17 \\
\hline 3 & 28.1 & 41 \\
\hline 4 & 17.1 & 25 \\
\hline 5 & 16.4 & 24 \\
\hline Self-rated impairment in daily activities & 95.5 & 149 \\
\hline Permanent attendance of a caregiver necessary & 39.1 & 61 \\
\hline \multicolumn{3}{|l|}{ Main caregiver $(\mathrm{n}=136)$} \\
\hline Partner & 86 & 117 \\
\hline Children & 7.4 & 10 \\
\hline Others & 6.6 & 9 \\
\hline \multicolumn{3}{|l|}{ Employment situation of the main caregiver $(n=119)$} \\
\hline Working caregiver & 47.1 & 56 \\
\hline Main caregiver stopped working because of patient's ALS & 5 & 6 \\
\hline Change of weekly working time because of patient's ALS & 14.3 & 17 \\
\hline Job change because of patient's ALS & 2.5 & 3 \\
\hline Drop in salary because of patient's ALS & 10.1 & 12 \\
\hline \multicolumn{3}{|l|}{ Housing situation $(\mathrm{n}=152)$} \\
\hline Family & 87.5 & 133 \\
\hline Alone & 10.5 & 16 \\
\hline Assisted living/foster home & 2 & 3 \\
\hline \multicolumn{3}{|l|}{ Employment $(\mathrm{n}=145)$} \\
\hline Employment no longer possible & 26.2 & 38 \\
\hline Working & 13.8 & 20 \\
\hline Retired, unemployed, homemaker & 60 & 87 \\
\hline \multicolumn{3}{|l|}{ Reasons for unemployability $(\mathrm{n}=34)$} \\
\hline Retired because of ALS & 61.8 & 21 \\
\hline Unable to work & 5.9 & 2 \\
\hline Unknown & 32.4 & 11 \\
\hline EQ-VAS score (max. 100) & $40(35)$ & \\
\hline EQ-5D-5L ${ }^{\mathrm{TM}}$ index value (max. 1) & $0.585(0.623)$ & \\
\hline
\end{tabular}

Table 1. Demographics. This table shows the most important patient characteristics, their disease stage (King's staging), and the impairment in their autonomy and working lives. The professional activity assessment of patients and of their main caregivers served as basis for the calculation of indirect costs. Abbreviations: IQR = interquartile range, $y=$ years, BMI $=$ Body-Mass-Index, $\mathrm{n}$ = number, ALS = amyotrophic lateral sclerosis, ALSFRS-R = Revised Amyotrophic Lateral Sclerosis Functional Rating Scale, EQ-VAS score $=$ self-rated health on a visual analogue scale (0-100). 


\begin{tabular}{lll} 
Table 2 Cost of illness $(\mathrm{COI})$ & Mean annual costs in $€(95 \% \mathrm{CI})$ & Ratio of total COI (percent) \\
\hline Direct medical costs & $\mathbf{2 8 , 0 8 7}(20,911-35,263)$ & 35.9 \\
Formal care & $8,888(2,601-15,174)$ & 11.4 \\
\hline Further therapies & $7,629(6,610-8,649)$ & 9.7 \\
\hline Hospitalisation & $4,568(2,991-6,145)$ & 5.8 \\
\hline Supportive devices & $2,785(2,032-3,538)$ & 3.6 \\
\hline Drugs & $2,190(1,971-2,409)$ & 2.8 \\
\hline Inpatient rehabilitation & $885(607-1162)$ & 1.1 \\
\hline Outpatient physician consultations & $612(515-710)$ & 0.8 \\
\hline Surgery & $189(114-263)$ & 0.2 \\
\hline Outpatient hospital consultations & $180(140-220)$ & 0.2 \\
\hline Psychological support & $161(29-293)$ & 0.2 \\
\hline Direct non-medical costs & $38,412(31,695-45,130)$ & 49.1 \\
Informal care & $36,152(29,621-42,683)$ & 46.2 \\
\hline Constructional alterations & $1,871(1,123-2,618)$ & 2.4 \\
\hline Travel expenses & $353(270-436)$ & 0.5 \\
\hline Legal support & $9(1-18)$ & 0.0 \\
\hline Other costs & $27(24-31)$ & 0.0 \\
\hline Indirect costs & $11,757(8,232-15,282)$ & 15.0 \\
\hline Total COI & $78,256(66,583-89,929)$ & 100.0 \\
\hline
\end{tabular}

Table 2. Cost of illness (COI). Incurred costs per ALS patient and year in the different cost categories from a societal perspective. Other costs consisted of e.g. ALS-related fitness centre membership and others. Due to rounding, percentages do not add up exactly. Abbreviations: $€=$ Euro, $\mathrm{CI}=$ confidence interval.

Table 3 Influencing factors on total COI

\begin{tabular}{llcc} 
Variable & Change in total costs, $€$ & $95 \%$ CI & $p$-value \\
\hline ALSFRS-R score (max. 48) & $-2,333$ & $-3,584$ to $-1,082$ & 0.000 \\
\hline Permanent attendance of a caregiver necessary & 22,178 & 2,684 to 41,671 & 0.026 \\
\hline Invasive ventilation & 47,803 & 5,112 to 90,493 & 0.029 \\
\hline Wheelchair use & 14,081 & 1,388 to 26,774 & 0.030 \\
\hline Underweight & 14,378 & $-9,564$ to 38,320 & 0.237 \\
\hline Classified into a care level & $-6,491$ & $-27,461$ to 14,479 & 0.541 \\
\hline Feeding tube use & 7,617 & $-17,849$ to 33,084 & 0.555 \\
\hline Currently working & $-6,150$ & $-28,304$ to 16,005 & 0.584 \\
\hline $\mathrm{n}$ & 127 & &
\end{tabular}

Table 3. Influencing factors on total COI. This multiple linear regression model showed significant influence of the ALSFRS-R score, wheelchair use, invasive ventilation, and the necessity of permanent attendance of another caregiver on total costs. The model was adjusted for statistical outliers. Abbreviations: $\mathrm{COI}=$ cost of illness, $€=$ Euro, $\mathrm{CI}=$ confidence interval, $\mathrm{ALSFRS}-\mathrm{R}=\mathrm{Revised}$ Amyotrophic Lateral Sclerosis Functional Rating Scale, $\mathrm{n}=$ number. 
Table 4A Influencing factors on EQ-VAS score

\begin{tabular}{llcc}
\hline Variable & Change in EQ-VAS score & $95 \%$ CI & p-value \\
\hline Classified into a care level & -14 & -22.3 to -5.6 & 0.001 \\
\hline Impaired in daily activities & -24.7 & -41.7 to -7.7 & 0.005 \\
\hline Wheelchair use & -8.8 & -16 to -4 & 0.030 \\
\hline Age & -0.3 & -0.6 to 0 & 0.034 \\
\hline Permanent attendance of a caregiver necessary & -8.3 & -16.1 to -0.5 & 0.037 \\
\hline $\mathrm{n}$ & 131 & & \\
\hline
\end{tabular}

Table 4B Influencing factors on EQ-5D-5L $\mathrm{L}^{\mathrm{TM}}$ index value

\begin{tabular}{lccc}
\hline Variable & Change in EQ-index score & $95 \%$ CI & p-value \\
\hline Permanent attendance of a caregiver necessary & -0.25 & -0.33 to -0.16 & 0.000 \\
\hline Wheelchair use & -0.17 & -0.22 to -0.12 & 0.000 \\
\hline Classified into a care level & -0.13 & -0.22 to -0.04 & 0.005 \\
\hline Impaired in daily activities & -0.15 & -0.28 to -0.02 & 0.023 \\
\hline Invasive ventilation & -0.13 & -0.28 to 0.03 & 0.103 \\
\hline Currently working & -0.02 & -0.12 to 0.08 & 0.692 \\
\hline $\mathrm{n}$ & 122 & & \\
\hline
\end{tabular}

Table 4. Influencing factors on HRQoL. This multiple linear regression model showed significant influence by mainly of loss of autonomy (classification into a care level, impairment in daily activities, wheelchair use and need of permanent attendance of a caregiver) on HRQoL. The model was adjusted for statistical outliers. Abbreviations: HRQoL = health related quality of life, $€=$ Euro, EQ-VAS score $=$ self-rated health on a visual analogue scale $(0-100), \mathrm{CI}=$ confidence interval, $\mathrm{n}=\mathrm{number}$.

\section{Figures}




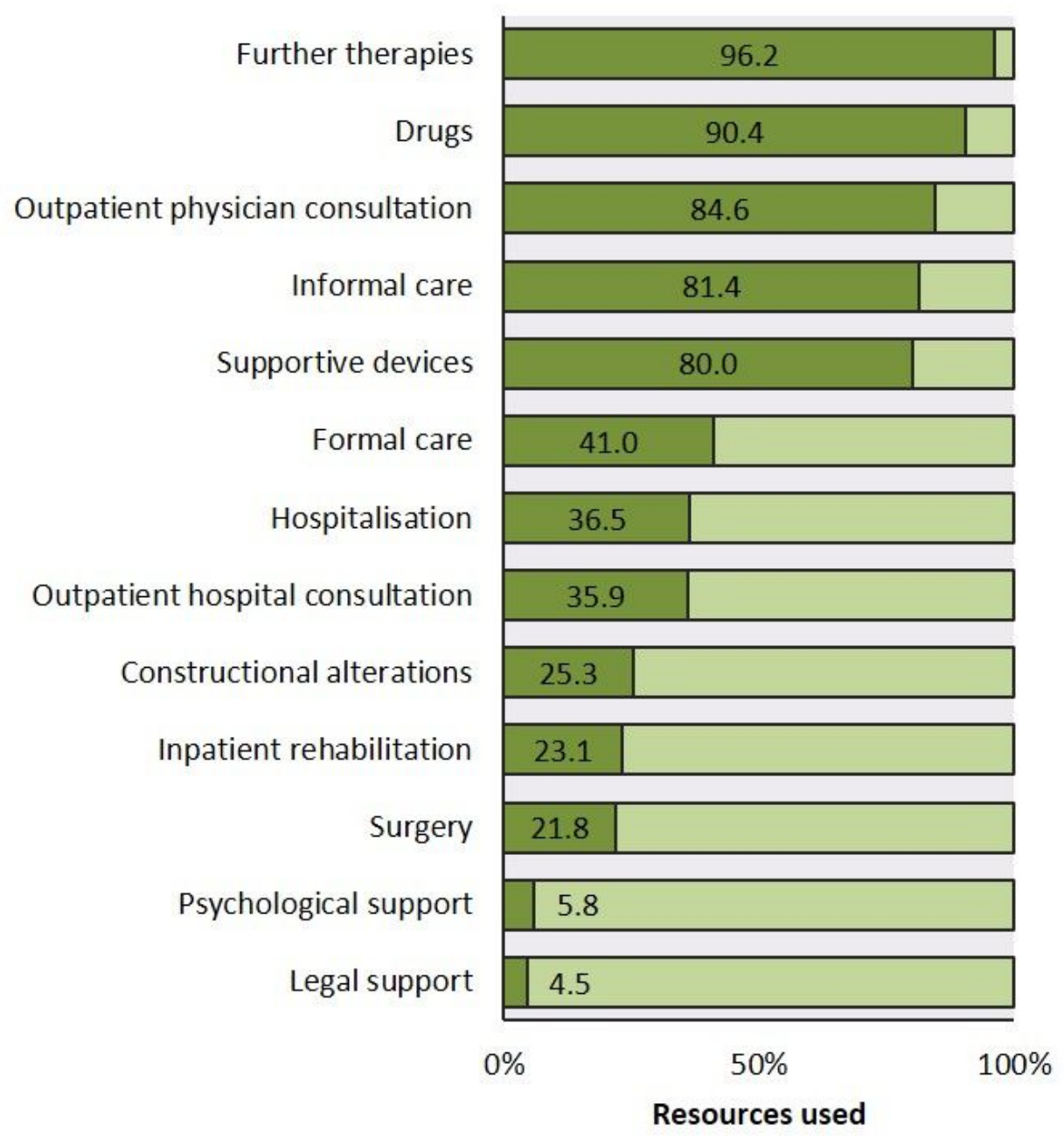

Used $\quad \square$ Did not use

\section{Figure 1}

Utilisation of medical resources. Figure 1 shows the proportion of the use of different medical resources. Further details are shown in additional file 1. 


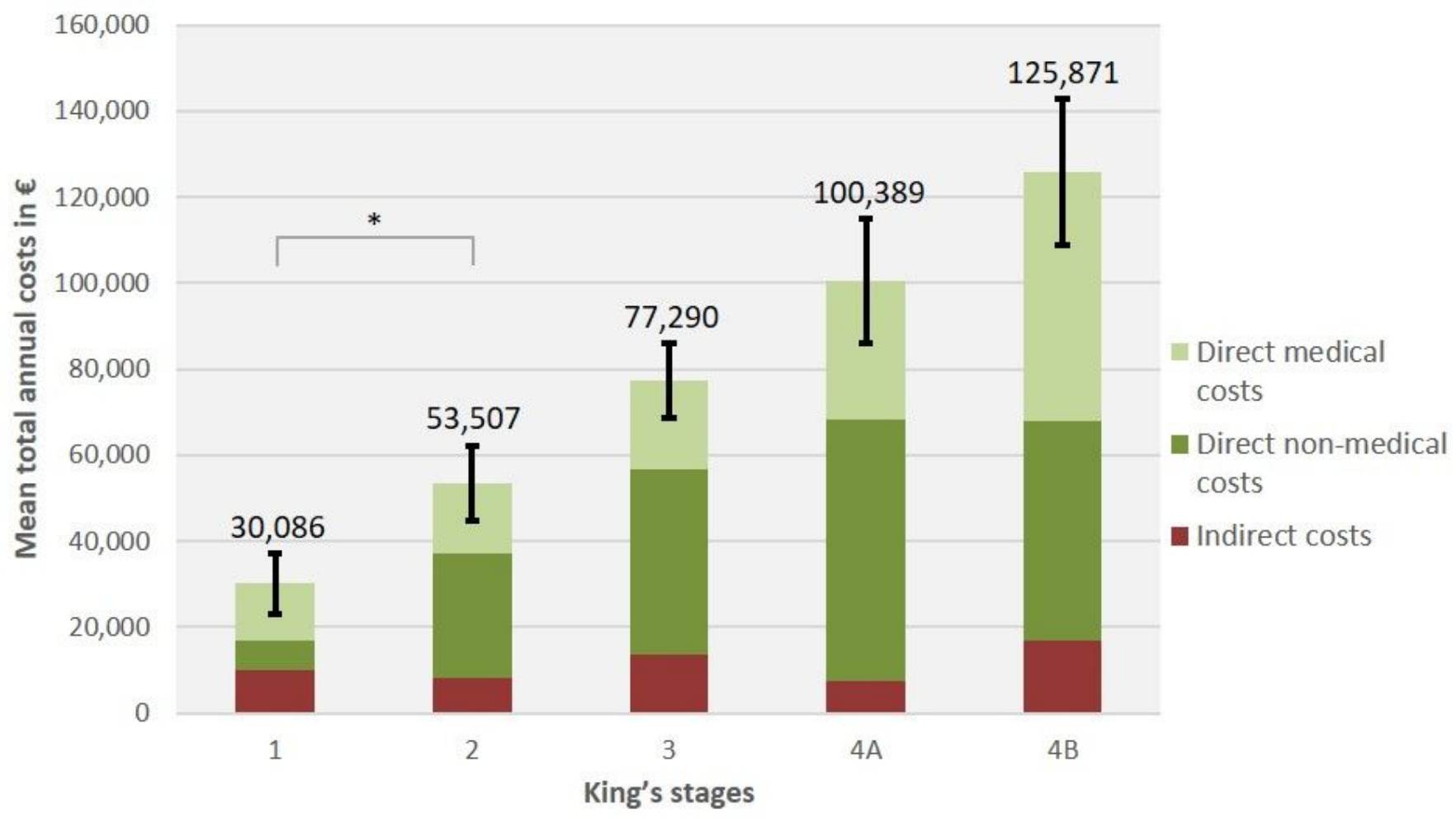

Figure 2

Annual cost of illness (COI) according to King's staging. Standard errors presented refer to the total annual costs. Significant positive correlations between King's staging and total costs ( $r s=0.482, p<0.001, n=156)$, between King's staging and direct medical costs $(r s=0.361, p<0.001, n=$ 156 ) and between King's staging and direct non-medical costs ( $r s=0.450, p<0.001, n=156)$. No significant correlations were found between King's staging and indirect costs $(r s=0.102, p=0.205, n=156)$. Abbreviations: $€=$ Euro. ${ }^{*}=p<0.05$. 

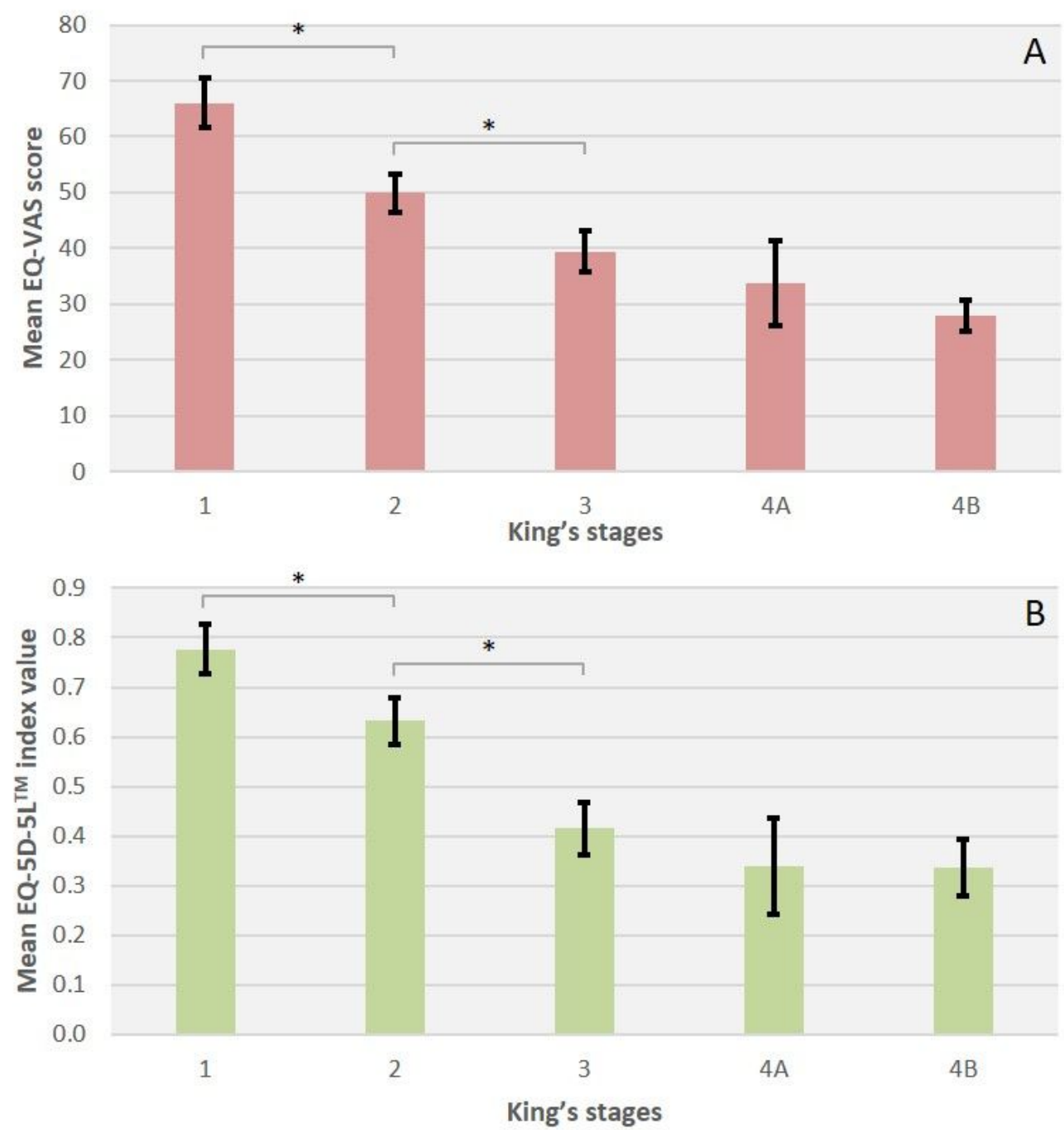

\section{Figure 3}

Health-related quality of life (HRQOL) according to King's staging. Mean scores are presented with standard errors. (A) shows mean EQ-VAS scores, (B) shows mean EQ-5D-5LTM index values. Significant negative correlation between King's staging and EQ-VAS score $(r s=-0.490, p<$ $0.001, n=141)$ as well as EQ-5D-5LTM index values $(r s=-0.477, p<0.001, n=141)$. Abbreviations: EQ-VAS score $=$ self-rated health on a visual analogue scale $(0-100){ }^{*}=p<0.05$. 


\section{King's stages}

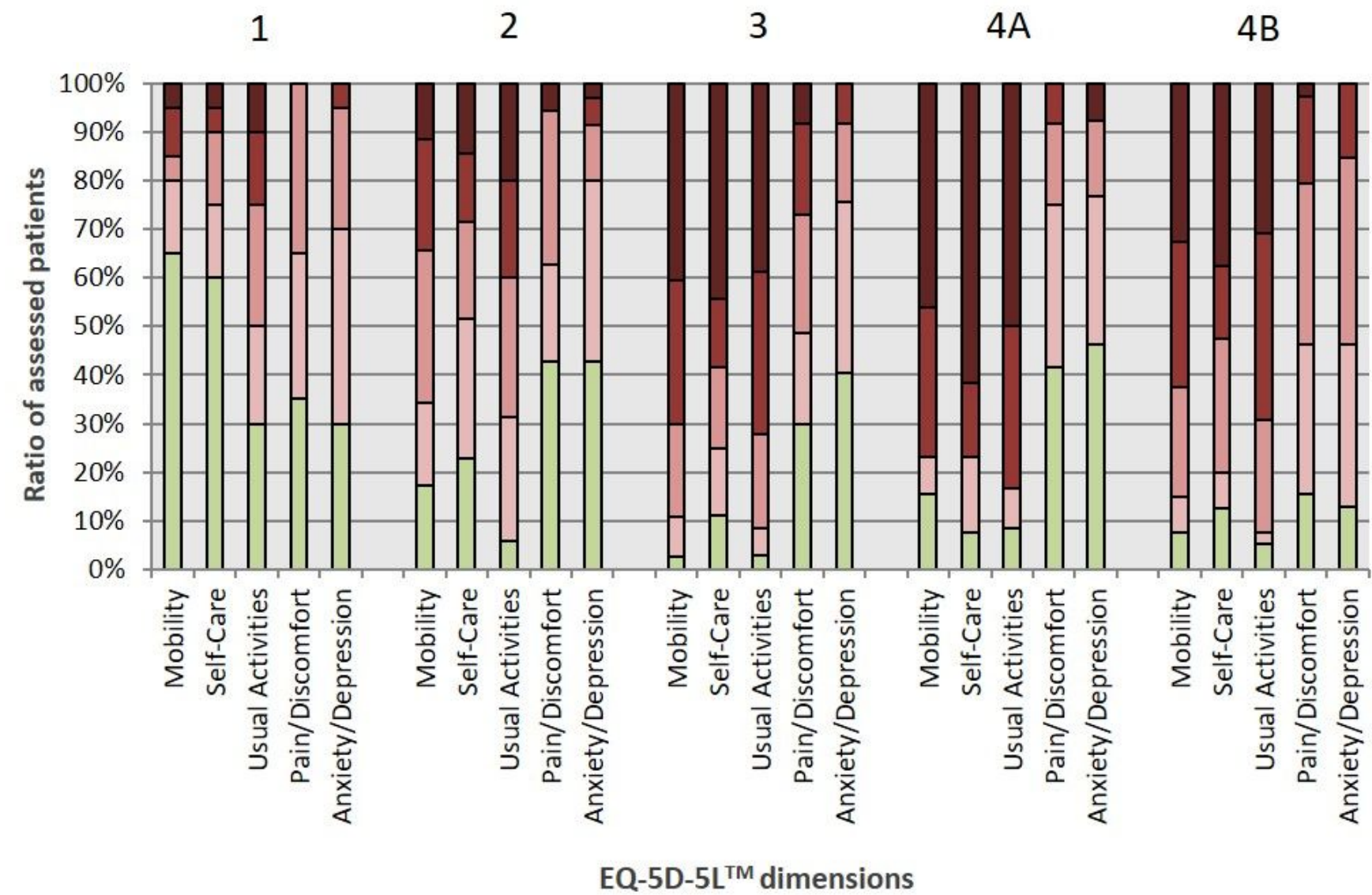

$\square$ No problems

$\square$ Severe problems

\section{$\square$ Some problems}

$\square$ Not able/extreme problems

Figure 4

Impairments in the five domains of EQ-5D-5LTM according to King's staging. Impairments in the five dimensions increased with disease severity, the domains Mobility, Self-Care and Usual Activities were impaired to a higher degree and remained in focus within the disease course.

\section{Supplementary Files}

This is a list of supplementary files associated with this preprint. Click to download.

- 20200219SchoenfelderEAdditionalfile2.docx

- 20200211SchoenfelderEAdditionalfile1.docx 